\title{
Selective Conversion of Glucose to 5-Hydroxymethylfurfural by Using L-Type Zeolites with Different Morphologies
}

\author{
María José Ginés-Molina ${ }^{1,+}{ }^{+}$Nur Hidayahni Ahmad ${ }^{2,+}$, Sandra Mérida-Morales ${ }^{1,+}$, \\ Cristina García-Sancho ${ }^{1}(\mathbb{D})$, Svetlana Mintova ${ }^{3}(\mathbb{D})$, Ng Eng-Poh $^{2, *(D)}$ and \\ Pedro Maireles-Torres $1, *$ (D) \\ 1 Departamento de Química Inorgánica, Cristalografía y Mineralogía (Unidad Asociada al ICP-CSIC) Facultad \\ de Ciencias, Universidad de Málaga, Campus de Teatinos, 29071 Málaga, Spain; \\ mariaj.gimo@uma.es (M.J.G.-M.); sandra_merida@uma.es (S.M.-M.); cristinags@uma.es (C.G.-S.) \\ 2 School of Chemical Sciences, Universiti Sains Malaysia, USM, Penang 11800, Malaysia; \\ nurhidayahni@gmail.com \\ 3 Normandie Université, ENSICAEN, UNICAEN, CNRS, LCS, 14000 Caen, France; mintova@ensicaen.fr \\ * Correspondence: epng@usm.my (E.-P.N.); maireles@uma.es (P.M.T.) \\ + These authors contributed equally to this work as first authors.
}

Received: 25 November 2019; Accepted: 13 December 2019; Published: 16 December 2019

\begin{abstract}
In the present work, the morphology of L-type zeolite (LTL topology) has been modified in order to evaluate the influence of several protonated-form LTL-zeolites with different morphologies on their stability and catalytic performance in the conversion of glucose into 5-hydroxymethylfurfural (5-HMF). Physico-chemical characterization of the LTL-based catalysts has revealed that the three types of morphologies (needle, short rod and cylinder) are active, providing complete glucose conversion and high 5-HMF yield values. The addition of $\mathrm{CaCl}_{2}$ had a positive influence on the catalytic performance. It was found that morphology influences the textural and acid properties of LTL-zeolites, and hence their catalytic performance. The best catalytic results have been obtained with the NEEDLE-LTL, showing nanoparticles with a length of $4.46 \mu \mathrm{m}$ and a width of $0.63 \mu \mathrm{m}$, which attains a $5-\mathrm{HMF}$ yield of $63 \%$, at $175^{\circ} \mathrm{C}$ after $90 \mathrm{~min}$ of reaction, and a glucose conversion of $88 \%$. The reusability study has revealed a progressive decrease in 5-HMF yield after each catalytic cycle. Different regeneration methods have been essayed without recovering the initial catalytic activity. The presence of organic molecules in micropores has been demonstrated by TG analysis, which are difficult to remove even after a regeneration process at $550{ }^{\circ} \mathrm{C}$.
\end{abstract}

Keywords: biomass; glucose; 5-hydroxymethylfurfural; LTL-zeolites; heterogeneous catalysis

\section{Introduction}

In recent years, much attention is being paid to the development of environmentally and economically viable synthetic routes and technologies for producing chemicals and fuels from non-fossil carbon sources as alternative to fossil raw materials [1]. In this context, biomass is emerging as a very promising sustainable feedstock, being the only widely available and renewable carbon source [2,3]. Lignocellulosic biomass, mainly composed by lignin, cellulose and hemicellulose, with an estimated annual production about $2 \times 10^{11}$ metric tons, is the most abundant source of carbohydrates, but physico-chemical treatments are required for its use as a raw material [4]. Although lignocellulose is a sustainable resource for production of biofuels and chemicals, it is necessary that this does not interfere with the food chain. The hydrolysis of cellulose and hemicellulose leads to monomeric $\mathrm{C}_{5}$ and $\mathrm{C}_{6}$ sugars, which can be converted into important platform molecules, such as 
furfural and 5-hydroxymethylfurfural (5-HMF), respectively, which are the starting point for the synthesis of a large variety of biofuels and chemicals [5,6]. For instance, 5-HMF can be transformed into 2,5-dimethylfuran [7] or levulinic acid [8,9], among others, which are key intermediates for the synthesis of pharmaceuticals, polymers or biofuels.

Although the dehydration of fructose to 5-HMF has largely been reported in the literature, glucose is preferred due to its abundance and low price [10]. There is not a general consensus about the mechanism of glucose dehydration to 5-HMF, even though a generally accepted route based on: (i) isomerization of glucose to fructose, and (ii) dehydration of fructose to 5-HMF [4]. The first step is considerably difficult and requires Lewis acid or basic sites, being the limiting factor for 5-HMF production. The reaction may be performed either in water, organic solvents or ionic liquids, in particular polar aprotic solvents. Homogeneous catalysts such as sulphuric or hydrochloric acids can be effective for the hydrolysis of cellulose to glucose, and even for the dehydration of fructose to 5-HMF. However, due to their corrosive properties which are hazardous for equipment, they are gradually replaced by heterogeneous catalysts. Besides, heterogeneous catalysts allow their easy separation from solution, recovery and reuse [11-13]. Different solid acid catalysts have been tested for dehydration of glucose to 5-HMF, such as $\gamma-\mathrm{Al}_{2} \mathrm{O}_{3}$ [14], zeolites [15], metal oxides like $\mathrm{TiO}_{2}$ or $\mathrm{ZrO}_{2}$ [12-15], mesoporous solids [16,17], inter alia.

Nevertheless, both solvent and catalyst must be considered as two key factors to attain high 5-HMF yields from $\mathrm{C}_{6}$ carbohydrates. A common strategy for 5-HMF production is the use of biphasic systems because this approach gives higher 5-HMF yields than systems employing only water. Usually, the biphasic medium is formed by the addition of organic solvents (toluene, methyl isobutyl ketone, among other) to an aqueous solution, or the addition of miscible organic solvents like tetrahydrofuran (THF) [18], to a saturated salt solution, which allows to extract the 5-HMF formed from the aqueous phase, preventing its further degradation and condensation [4].

In order to prevent these side reactions, Román-Leshkov et al. [19] employed inorganic salts in a biphasic system for dehydration of fructose to 5-HMF and concluded that the salting-out effect leading to a higher partition coefficient, limiting the individual cationic or anionic contributions, so then it is feasible to correlate to the interaction of all ionic species. In this context, it has also been reported that divalent cations interact more strongly with saccharides than the monovalent ones [20]. Thus, Combs et al. [21] observed that alkaline earth metal cations can form bidentate complexes with glucose, which accelerated its transformation. Later, our research group studied the beneficial effects of $\mathrm{CaCl}_{2}$ on glucose dehydration to 5-HMF in the presence of $\mathrm{Al}_{2} \mathrm{O}_{3}$ as catalyst, in such a way that the addition of $\mathrm{CaCl}_{2}$ to the reaction medium notably improved the catalytic performance, even at very short reaction times, due to the interaction between $\mathrm{Ca}^{2+}$ ions and glucose molecules, which favored the $\alpha$-D-glucopyranose formation [14].

Concerning the use of zeolites for glucose dehydration, different acidic ZSM-5-zeolites (H-, Feand $\mathrm{Cu}-\mathrm{ZSM}-5$ ) were prepared and studied by modifying several experimental variables [15]. It was demonstrated the positive effect of the addition of inorganic salt $(\mathrm{NaCl})$ to a biphasic water/methyl isobutyl ketone (MIBK) system, since a glucose conversion of $80 \%$, with a HMF yield of $42 \%$ was attained at $195^{\circ} \mathrm{C}$, after $30 \mathrm{~min}$, by using a H-ZSM-5-zeolite, which had the lowest Lewis/Brönsted ratio among the studied zeolites. Later, the H-ZSM-5-zeolite was compared with $\mathrm{H}-\mathrm{Y}$ and $\mathrm{H}$ - $\beta$-zeolites, in order to assess the influence of the textural properties on the catalytic performance in glucose dehydration [22]. Under similar experimental conditions, by using a H- $\beta$-zeolite, the highest 5 -HMF yield $(56 \%)$ was reached, thus demonstrating the benefit of mesoporosity in this catalytic process.

Recently, by using a bifunctional $\mathrm{Cr} / \beta$ zeolite, a high selectivity to $5-\mathrm{HMF}$ with a yield of $72 \%$, was found at $150^{\circ} \mathrm{C}$, after $90 \mathrm{~min}$, by adding $\mathrm{NaCl}$ to a biphasic $\mathrm{H}_{2} \mathrm{O} / \mathrm{THF}$ system [23]. After three consecutive catalytic cycles, the catalytic activity slightly decreased, but after a thermal treatment was almost recovered.

Morphological or textural characteristics play a highly important role when discussing catalytic activity in a chemical reaction [24]. Nevertheless, the morphological roles of zeolite in glucose 
dehydration are still not completely understood, hence further investigation to reveal this effect in the dehydration reaction is of the utmost importance. The aim of this work is a thorough study of glucose dehydration for 5-HMF production (Scheme 1) using protonated L-type (H-LTL) zeolites with different morphologies, which have been characterized and their catalytic performance has been correlated with their textural and acid-base properties.

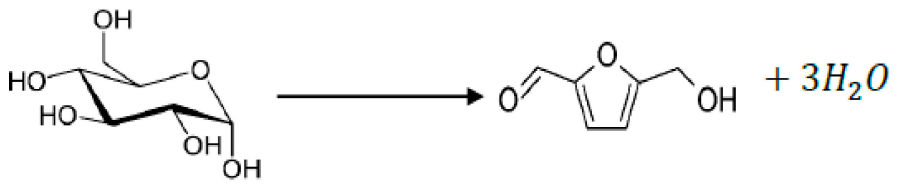

Scheme 1. Reaction pathway of glucose to 5-hydroxymethylfurfural.

\section{Results and Discussion}

\subsection{Catalyst Characterization}

The choice of a LTL zeolitic framework to evaluate the influence of the morphology (short rod, cylinder and needle) on the catalytic performance in glucose dehydration to HMF arises from the dimensions of pore mouth and channels of this crystallographic structure (Figure 1). These allow the entrance of glucose molecules to reach active acid sites, and 5-hydroxymethylfurfural can easily go out, leaving active sites available for new sugar molecules.

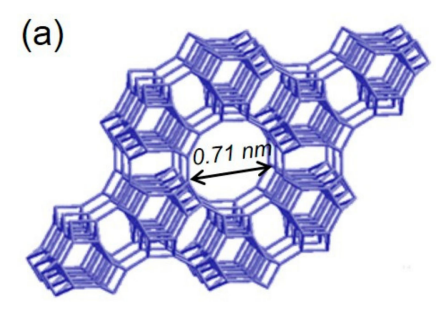

(b)

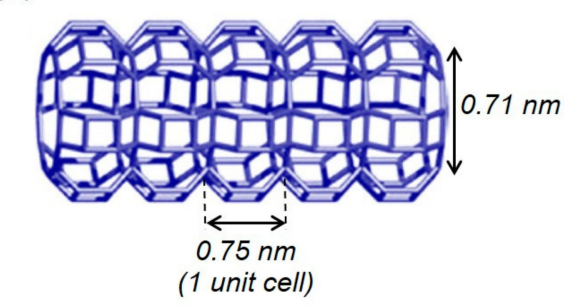

(c)

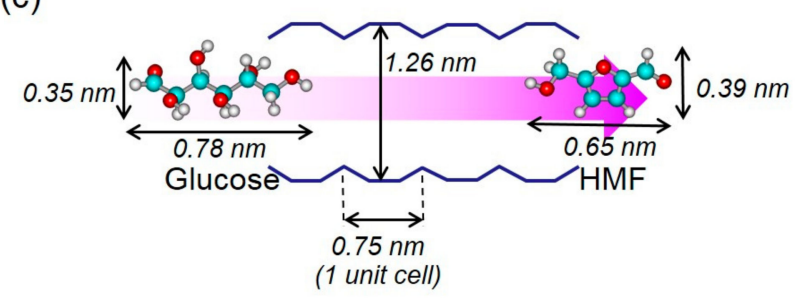

Figure 1. (a) Structure of LTL-zeolite view along [001] plane illustrating its hexagonal framework. (b) An LTL channel view normal to [001] plane that consists of $0.75 \mathrm{~nm}$ unit cells with a pore opening of $0.71 \mathrm{~nm}$. (c) Schematic illustration of diffusion of glucose as reactant and HMF as product in the 12-membered ring channel of LTL zeolite.

The X-ray diffraction patterns of H-LTL-zeolites exhibit many narrow diffraction peaks at $2 \theta=5.55^{\circ}$ (100), $11.10^{\circ}(200), 11.77^{\circ}(001), 18.89^{\circ}$ (210), $15.23^{\circ}(111), 19.31^{\circ}(220), 20.09^{\circ}(310), 20.47^{\circ}$ (301), etc. which can be assigned to the hexagonal LTL-type framework (PDF 98-007-4170) (Figure 2). In all cases, no additional crystalline phase is detected and the crystallinity of the solids is preserved after ion-exchange and calcination treatments. 


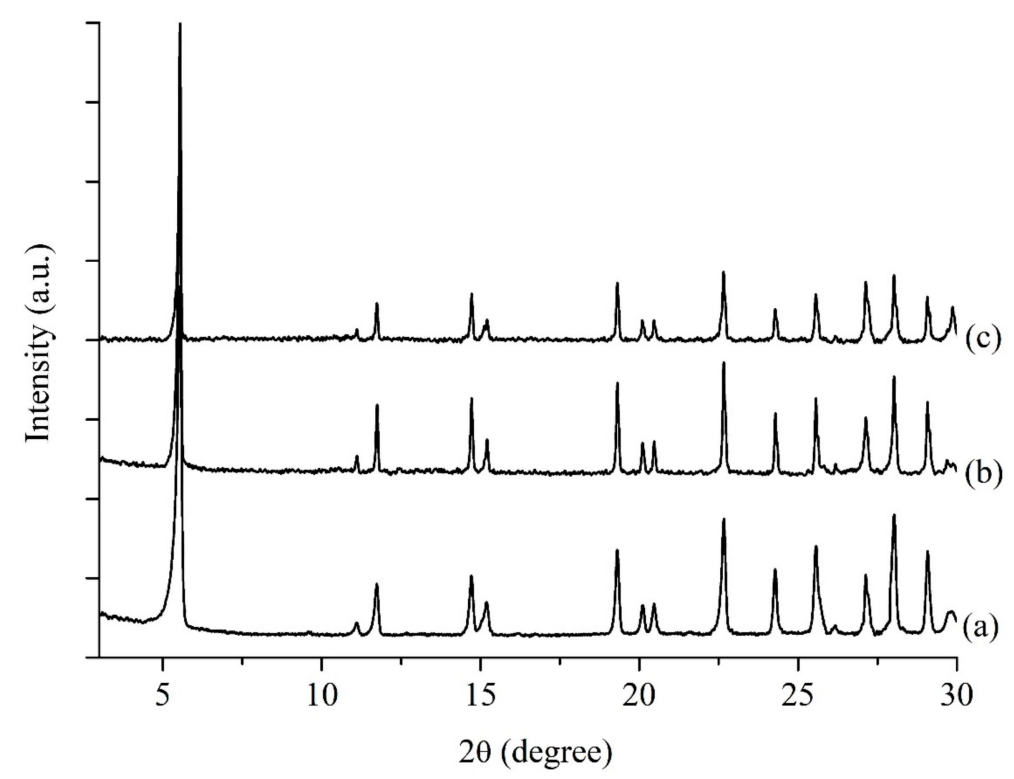

Figure 2. XRD patterns of (a) ROD-LTL, (b) NEEDLE-LTL and (c) CYL-LTL zeolites.

Concerning the chemical composition of LTL-zeolites, the $\mathrm{Si} / \mathrm{Al}$ molar ratio values obtained from ICP-OES are close to 3, which are lower than that used in the synthesis gel (10) (Table 1). The comparison between the bulk and surface chemical composition data, deduced from ICP-OES and XPS, respectively, points an enrichment of $\mathrm{Si}$ on the surface of LTL-zeolites. This could be explained by the higher Si/Al molar ratio (10) used in the synthesis of these zeolites. However, the inherent error associated with the semi-quantitative analysis by XPS must be taken into account. After the ion exchange process between $\mathrm{K}^{+}$and $\mathrm{NH}_{4}{ }^{+}$ions, not all the alkaline cations are removed, which can be due to the existence of strong acid sites remaining dissociated and neutralized by $\mathrm{K}^{+}$cations, even in the presence of an excessive ammonium solution. Therefore, the K/Al molar ratio is lower than 1 for NEEDLE-LTL and ROD-LTL, indicating that, although acid sites are protonated, a fraction of sites is still occupied by $\mathrm{K}^{+}$ ions. This fraction is even higher for the CYL-LTL, where its value closed to 1 would point out that this morphology is the less favorable for the ion-exchange process.

Table 1. XPS and ICP-OES (* in parentheses) data of LTL-zeolites.

\begin{tabular}{|c|c|c|c|c|c|c|}
\hline & \multicolumn{4}{|c|}{ Binding Energy (eV) } & \multirow{2}{*}{$\begin{array}{l}\text { Si/Al Molar } \\
\text { Ratio * }\end{array}$} & \multirow{2}{*}{$\begin{array}{l}\text { K/Al Molar } \\
\text { Ratio * }\end{array}$} \\
\hline & Si 2p & Al 2p & O 1s & $\mathrm{K} 2 \mathrm{p}_{3 / 2}$ & & \\
\hline NEEDLE-LTL & 102.8 & 74.3 & 532.1 & 293.3 & $4.23(3.00)$ & $0.45(0.63)$ \\
\hline ROD-LTL & 102.9 & 74.5 & 532.2 & 293.4 & $4.54(2.90)$ & $0.45(0.55)$ \\
\hline CYL-LTL & 103.2 & 74.6 & 532.4 & 293.7 & $4.43(3.45)$ & $1.28(1.07)$ \\
\hline
\end{tabular}

X-ray photoelectron spectroscopy (XPS) has been used to get insights into the surface nature of LTL- zeolites. In all cases, the binding energies of Si $2 p(102.8-103.2 \mathrm{eV}), \mathrm{Al} 2 \mathrm{p}(74.3-74.6 \mathrm{eV})$ and O 1s (532.1-532.4 eV) are typical of these elements forming part of microporous aluminosilicates [25]. As regards the $K 2 p$ spectra, they exhibit the characteristic doublet with the $K 2 p_{3 / 2}$ at 293.3-293.7 eV, and a spectral separation of $2.8 \mathrm{eV}$, typical of $\mathrm{K}^{+}$ions [26].

On the other hand, the textural properties reveal that all zeolites maintain high surface area values, being the largest one for short rod morphology (Table 2). As expected, these zeolites are mainly microporous solids, with a percentage of microporous surface area higher than $95 \%$. 
Table 2. Textural and acid properties of LTL-zeolites.

\begin{tabular}{|c|c|c|c|c|c|c|}
\hline & $\begin{array}{l}S_{\text {Langmuir }} \\
\left(\mathrm{m}^{2} \mathrm{~g}^{-1}\right)\end{array}$ & $\begin{array}{c}S_{\text {micro }} \\
\left(\mathrm{m}^{2} \mathrm{~g}^{-1}\right)\end{array}$ & $\begin{array}{c}V_{p} \\
\left(\mathrm{~cm}^{3} \mathrm{~g}^{-1}\right)\end{array}$ & $\begin{array}{l}\text { Length } \\
(\mu \mathrm{m})\end{array}$ & $\begin{array}{l}\text { Width } \\
(\mu \mathrm{m})\end{array}$ & $\begin{array}{l}\text { Total Acidity } \\
\left.(\mu \mathrm{mol} \mathrm{m})^{-2}\right)^{*}\end{array}$ \\
\hline NEEDLE-LTL & 248 & 235 & 0.100 & 4.46 & 0.63 & 6.73 \\
\hline ROD-LTL & 303 & 293 & 0.120 & 1.43 & 1.38 & 6.17 \\
\hline CYL-LTL & 219 & 199 & 0.090 & 3.70 & 0.97 & 4.88 \\
\hline
\end{tabular}

The microporous nature of these LTL-based zeolites can be easily confirmed by the shape of their adsorption-desorption isotherms of $\mathrm{N}_{2}$ at $-196^{\circ} \mathrm{C}$, which are Type I in the IUPAC classification, typical of microporous solids (Figure 3). The slight hysteresis loop could be associated to some mesoporosity generated during treatments used for synthesizing their protonated forms, probably associated to interparticular voids $[27,28]$, which is corroborated by the pore size distribution curves (Figure 3, right).
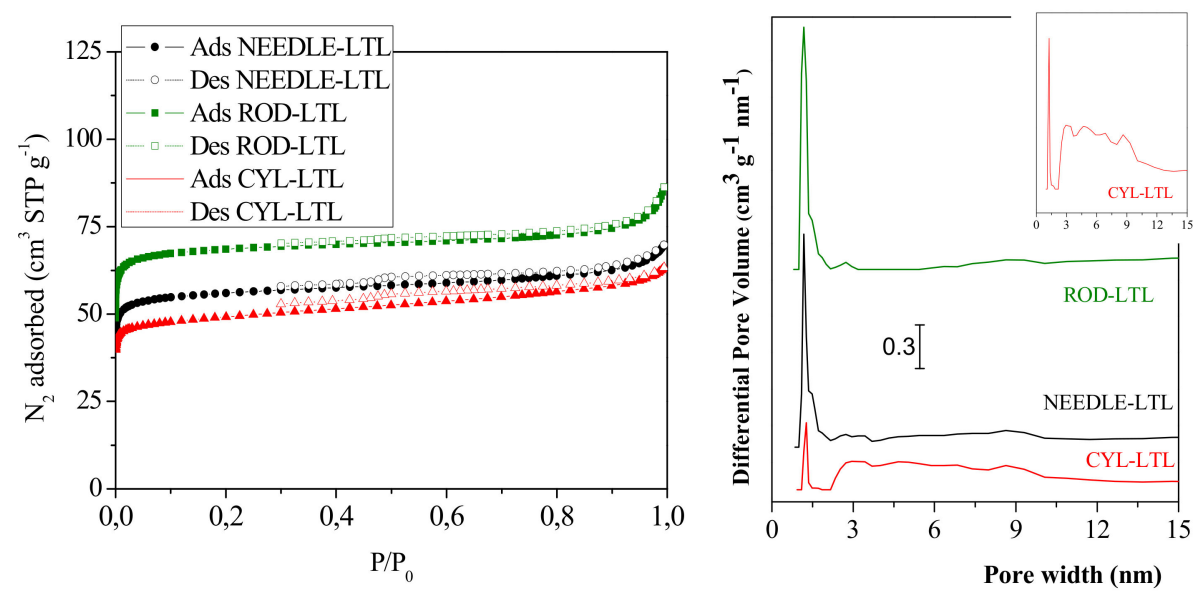

Figure 3. $\mathrm{N}_{2}$ adsorption-desorption isotherms (left) and pore size distributions (right) of LTL-zeolites at $-196{ }^{\circ} \mathrm{C}$.

The different morphologies are more clearly appreciated in the scanning electron micrographs (Figure 4), where micrometric particles are observed, whose dimensions and shapes fit in really well with short rods, needles and cylinders (Table 2).

On the other hand, the chemical environment of aluminium has been analyzed by ${ }^{27} \mathrm{Al}$ MAS-NMR spectroscopy (Figure 5). Extra-framework octahedral Al species are associated to a resonance signal at a chemical shift near $0 \mathrm{ppm}$, whereas tetrahedral $\mathrm{Al}$ in crystallographic sites in the zeolite framework appears at about $60 \mathrm{ppm}$. This latter signal is observed in all cases, and the absence of broadening effect at lower chemical shift values could discard the existence of pentacoordinated or distorted tetrahedral aluminium, reported in other microporous aluminosilicates, which give rise to signals at 30 and $47 \mathrm{ppm}$, respectively [29-31]. The small contribution at $0 \mathrm{ppm}$ is associated to extra-framework Al species, but this is absent in the MAS-NMR spectrum of CYL-LTL, where all Al seems to be in tetrahedral coordination. 

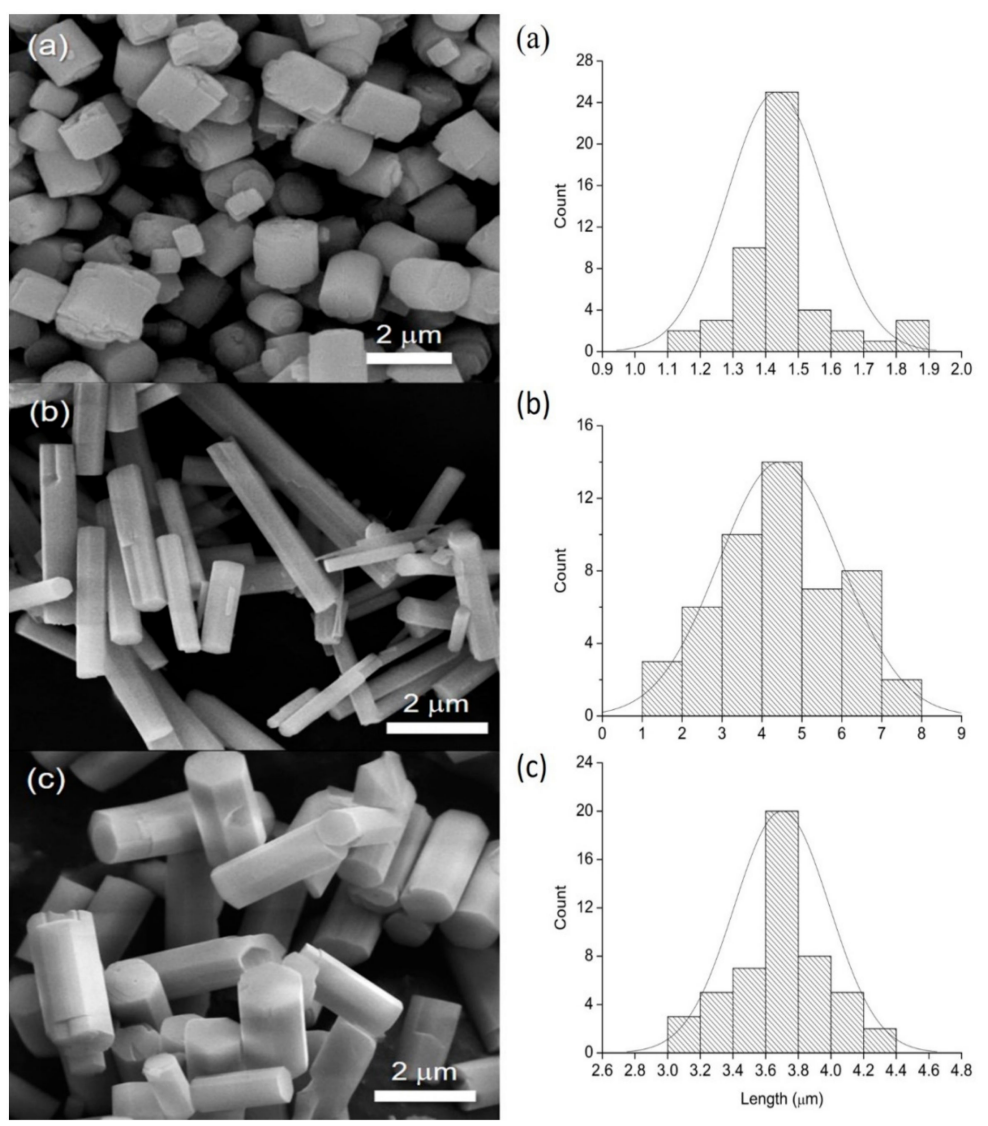

(b)

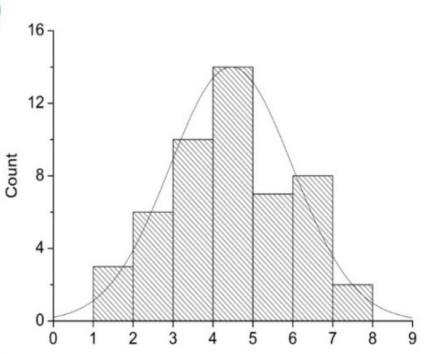

(c)

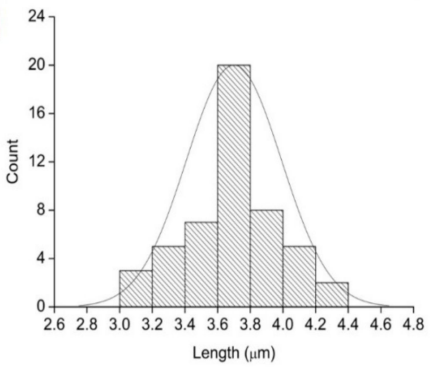

Figure 4. SEM images (left) and particle size distribution histograms (right) of LTL-zeolite crystals synthesized of (a) ROD-LTL, (b) NEEDLE-LTL and (c) CYL-LTL. Scale bar $=2 \mu \mathrm{m}$.

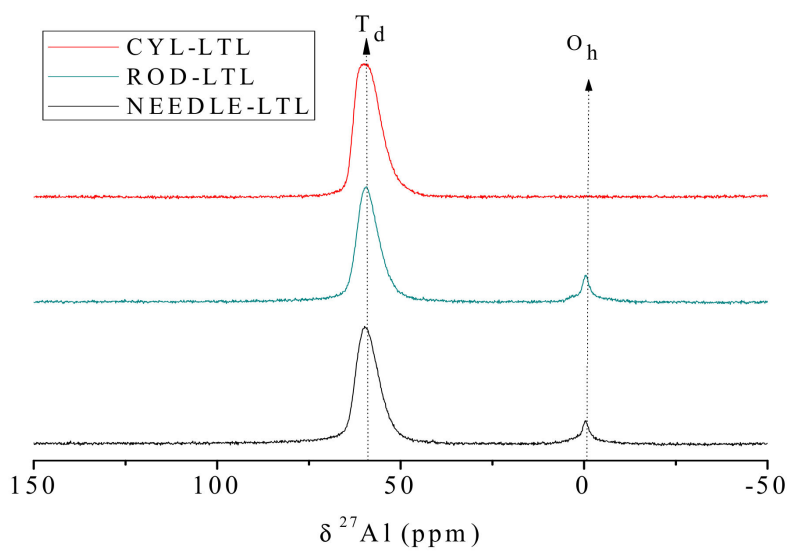

Figure 5. Solid state ${ }^{27}$ Al-NMR spectra of LTL-zeolites.

The total acidity of catalysts was determined from ammonia temperature-programmed desorption $\left(\mathrm{NH}_{3}-\mathrm{TPD}\right)$, whereas the nature (Brönsted or Lewis) of acid sites was studied from pyridine adsorption coupled to FTIR spectroscopy. Figure 6 displays the amount of ammonia desorbed in different temperature ranges, which have been assigned to weak $\left(100-200^{\circ} \mathrm{C}\right)$, medium $\left(200-300^{\circ} \mathrm{C}\right)$ and strong $\left(300-550^{\circ} \mathrm{C}\right)$ acid sites. The total acidity follows the order: ROD-LTL $\left(1874 \mu \mathrm{mol} \mathrm{g}{ }^{-1}\right)>$ NEEDLE-LTL $\left(1672 \mu \mathrm{mol} \mathrm{g}^{-1}\right)>$ CYL-LTL $\left(1065 \mu \mathrm{mol} \mathrm{g}^{-1}\right)$, being strong acid sites predominant in all cases. This acidity order is the same found for Langmuir surface area values (Table 2). 


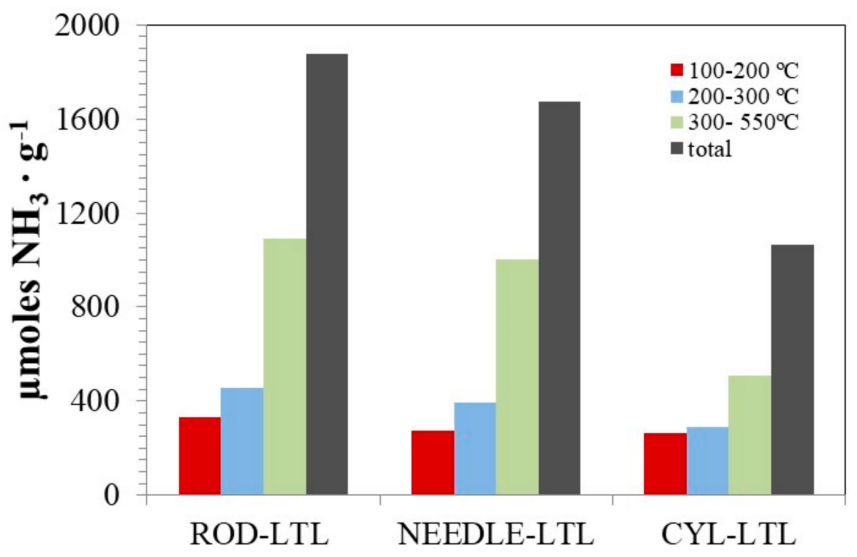

Figure 6. $\mathrm{NH}_{3}$ desorption of LTL-based zeolites, as a function of the strength: weak $\left(100-200{ }^{\circ} \mathrm{C}\right)$, medium $\left(200-300^{\circ} \mathrm{C}\right)$ and strong $\left(300-550{ }^{\circ} \mathrm{C}\right)$.

The nature of acid sites (Brönsted and/or Lewis) has been studied by pyridine adsorption coupled to FTIR spectroscopy. The concentration of Lewis and Brönsted acid sites after adsorption and subsequent desorption of pyridine at 150 and $300{ }^{\circ} \mathrm{C}$ is given in Table 3 . The lowest concentration of both Lewis and Brönsted acid sites is found for the ROD-LTL-zeolite, which after evacuation at $300{ }^{\circ} \mathrm{C}$ does not exhibit Lewis acidity. The other two zeolites (CYL- and NEEDLE-LTL) exhibit similar concentrations of strong Brönsted and Lewis acid sites, calculated from pyridine amount remaining on catalysts after evacuation at $300^{\circ} \mathrm{C}$. Moreover, these two zeolites possess a similar $\mathrm{B} / \mathrm{L}$ molar ratio (4.76 and 4.86 , respectively).

It has been previously reported that Brönsted acid sites could be associated to distorted tetrahedral $\mathrm{Al}$ species located in the zeolite framework, whereas distorted pentacoordinated $\mathrm{Al}$ species have been associated to Lewis acid sites in zeolites [32].

Table 3. Surface acidity of LTL-zeolites with different morphology at different temperature.

\begin{tabular}{|c|c|c|c|c|c|c|c|c|}
\hline & \multicolumn{6}{|c|}{ Py-FTIR Acidity ( $\mu \mathrm{mol} / \mathrm{g})$} & \multirow{2}{*}{\multicolumn{2}{|c|}{$\mathrm{B} / \mathrm{L}$}} \\
\hline & \multicolumn{2}{|c|}{ Lewis (L) } & \multicolumn{2}{|c|}{ Brönsted (B) } & \multicolumn{2}{|c|}{ Total $(\mathrm{L}+\mathrm{B})$} & & \\
\hline & $150{ }^{\circ} \mathrm{C}$ & $300^{\circ} \mathrm{C}$ & $150^{\circ} \mathrm{C}$ & $300^{\circ} \mathrm{C}$ & $150{ }^{\circ} \mathrm{C}$ & $300{ }^{\circ} \mathrm{C}$ & $150^{\circ} \mathrm{C}$ & $300^{\circ} \mathrm{C}$ \\
\hline ROD-LTL & 89.7 & 24.40 & 101.1 & 84.4 & 152.23 & 84.51 & 3.52 & - \\
\hline CYL-LTL & 126.08 & 32.08 & 128.07 & 152.85 & 254.15 & 184.93 & 1.02 & 4.76 \\
\hline NEEDLE-LTL & 120.55 & 31.76 & 161.39 & 154.50 & 281.95 & 186.26 & 1.34 & 4.86 \\
\hline
\end{tabular}

\subsection{Catalytic Study}

These zeolites have been evaluated as acid catalysts in the dehydration of glucose to 5-hydroxymethylfurfural, an important platform molecule for the synthesis of biofuels and high value-added chemicals [33]. Although the mechanism involved in glucose dehydration to 5-HMF seems to depend on type of catalyst, nature of solvent, among other parameters, it is broadly accepted that the rate-determining step is the isomerization of glucose to fructose [4]. For this reason, most of studies have used fructose as starting sugar. The isomerization process is catalyzed by Lewis acid or basic sites, whereas dehydration of fructose to 5-HMF requires the participation of Brönsted acid sites. The production of 5-HMF from glucose has two main drawbacks associated to the catalytic process, that is, the formation of by-products, such as soluble/insoluble polymers and humins, and the rehydration of 5-HMF for giving rise to levulinic and formic acids. These processes decrease the 5-HMF yield and, in some cases, provoke the catalyst deactivation. In this sense, the use of organic co-solvents together with the aqueous phase containing carbohydrates has been usually reported as a suitable strategy for improving 5-HMF yield. Among these organic solvents, MIBK is one of the 
most solvents often used due to their benign physico-chemical properties [34]. In this work, a biphasic water-MIBK system was employed to study the dehydration of glucose to 5-HMF.

Moreover, previous studies have demonstrated that the addition of inorganic salts to biphasic phases ameliorates the extraction of 5-HMF from biphasic systems $[14,16,19]$. In particular, $\mathrm{CaCl}_{2}$ exerts a positive effect on the catalytic performance, even at very short reaction times $[14,35]$. This was explained by the interaction between $\mathrm{Ca}^{2+}$ ions and carbohydrates (glucose and xylose), modifying the corresponding anomeric equilibrium towards the anomer $\alpha$ more prone for the dehydration process, as was concluded from ${ }^{1} \mathrm{H}-\mathrm{NMR}$ spectroscopy data.

In this sense, the catalytic activity of the LTL-zeolites was studied with and without $\mathrm{CaCl}_{2}$ addition (Figure 7). The positive effect is clearly observed, since at $150{ }^{\circ} \mathrm{C}$, after $60 \mathrm{~min}$ of reaction and in the absence of inorganic salt, the conversion of glucose is lower than $20 \%$ and in this case the formation of $5-\mathrm{HMF}$ is barely detected (5-HMF yield $<1 \%$ ). However, the addition of $\mathrm{CaCl}_{2}$ outstandingly improves the glucose conversion until values higher than $95 \%$ for ROD-LTL, with a 5-HMF yield of $58.5 \%$, whereas the rest of catalysts attain conversion and 5-HMF yield values higher than $75 \%$ and $25 \%$, respectively. Therefore, these data confirm previous results attained with other families of catalysts in the presence of inorganic salts $[15,19]$.

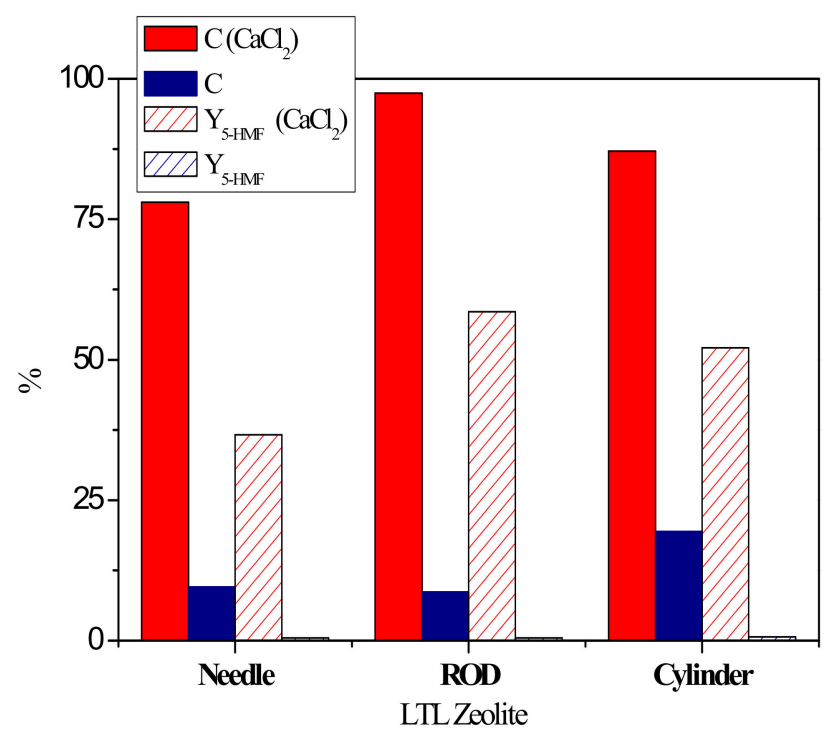

Figure 7. Effect of the addition of $\mathrm{CaCl}_{2}$ on the catalytic performance (C: glucose conversion; Y: yield) (Experimental conditions: $0.15 \mathrm{~g}$ glucose, $0.05 \mathrm{~g}$ catalyst, $1.5 \mathrm{~mL}$ water, $3.5 \mathrm{~mL} \mathrm{MIBK}$, Temperature $=150{ }^{\circ} \mathrm{C}$; time $\left.=60 \mathrm{~min}, \mathrm{CaCl}_{2}=0.65 \mathrm{~g} \mathrm{~g}_{\mathrm{H} 2 \mathrm{O}}{ }^{-1}\right)$.

The improving effect of $\mathrm{CaCl}_{2}$ addition on the catalytic performance of this series of LTL-based catalysts is evident. However, an additional catalytic study was performed in order to evaluate the contribution of $\mathrm{CaCl}_{2}$ to the overall catalytic activity. For this, $\mathrm{CaCl}_{2}\left(0.65 \mathrm{~g} \mathrm{~g}_{\mathrm{H} 2 \mathrm{O}}{ }^{-1}\right)$ was put in contact with glucose in the biphasic system, and compared with the same system to which the NEEDLE-LTL catalyst was added. The data reveal that, in the absence of catalyst, after $3 \mathrm{~h}$ at $150{ }^{\circ} \mathrm{C}$, the glucose conversion was $47.1 \%$, with a $5-\mathrm{HMF}$ yield of $16.8 \%$ (Figure 8 ).

However, under similar experimental conditions, this catalyst exhibits better catalytic performance, attaining a conversion of $86.9 \%$ and a $5-\mathrm{HMF}$ yield of $44.0 \%$. The catalytic activity in the presence of $\mathrm{CaCl}_{2}$ might be explained by the formation of $\alpha$-anomer in the presence of this salt, as it has been demonstrated in previous studies [14], which could easily be dehydrated due to the thermal contribution (non-catalyzed process) to the overall catalytic performance. 


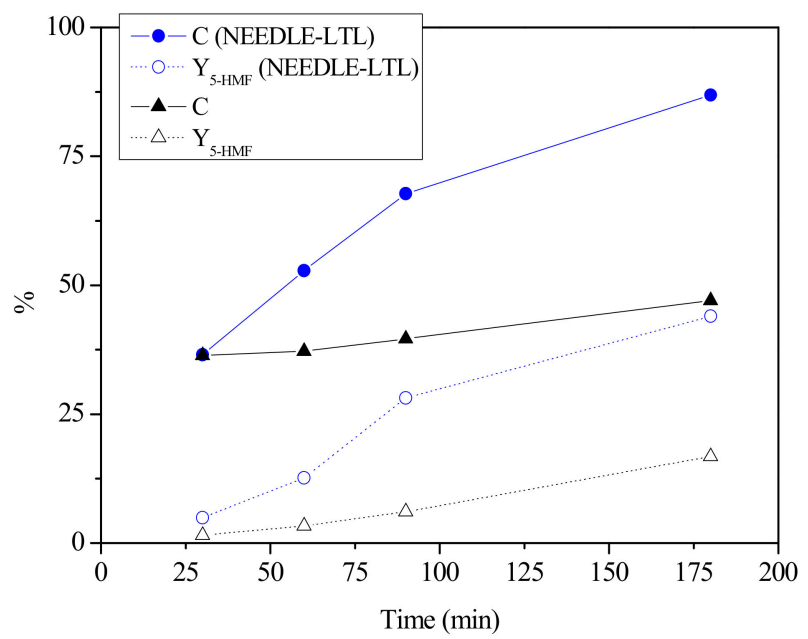

Figure 8. Catalytic performance of $\mathrm{CaCl}_{2}$ and $\mathrm{CaCl}_{2}$ /NEEDLE-LTL (C: glucose conversion; Y: yield) (Experimental conditions: $0.15 \mathrm{~g}$ glucose, straight line: $0.65 \mathrm{~g}_{\mathrm{H} 2 \mathrm{O}}{ }^{-1}$ and $0.05 \mathrm{~g}$ NEEDLE-LTL and dash line: $0.65 \mathrm{~g} \mathrm{~g}_{\mathrm{H} 2 \mathrm{O}}{ }^{-1}, 1.5 \mathrm{~mL}$ water, $3.5 \mathrm{~mL}$ MIBK, Temperature $=150^{\circ} \mathrm{C}$ ).

The kinetics of the dehydration process with LTL-based catalysts were studied at $150{ }^{\circ} \mathrm{C}$ (Figure 9), and similar conversion curves were obtained for the three catalysts, in spite of their different acid properties (Table 2) and morphologies. However, at intermediate reaction times, the 5-HMF yield values are lower for CYL-LTL, which could be explained by considering its lower acidity, although its mesoporous character could compensate the lower concentration of acid sites in this catalyst. In this study, the highest 5-HMF yield (50.3\%) was attained after 300 min with the ROD-LTL catalyst.

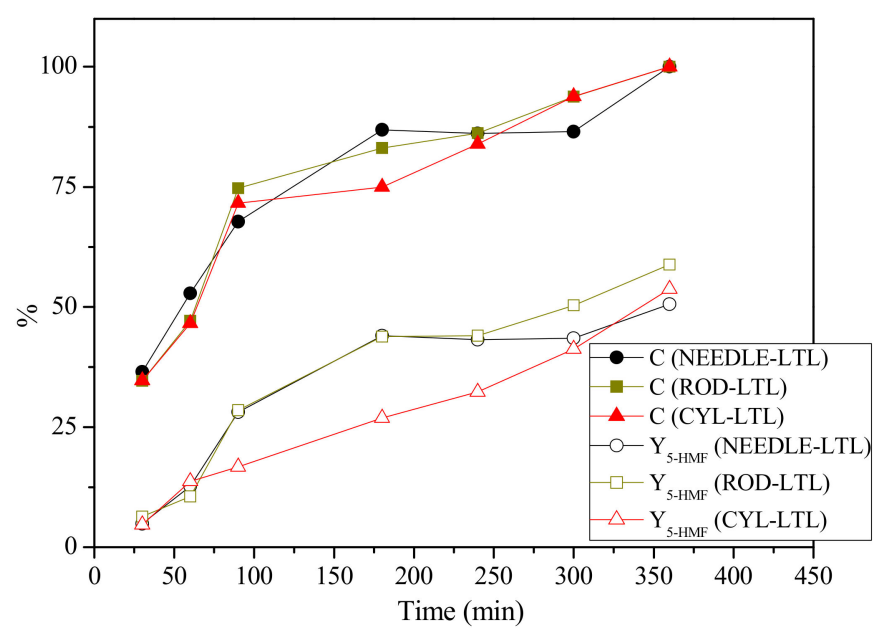

Figure 9. Kinetics of glucose dehydration (C: glucose conversion; $\mathrm{Y}$ : yield) (Experimental conditions: 0.15 g glucose, 0.05 g catalyst, $1.5 \mathrm{~mL}$ water, $3.5 \mathrm{~mL}$ MIBK, Temperature $=150{ }^{\circ} \mathrm{C} ; \mathrm{CaCl}_{2}=0.65 \mathrm{~g} \mathrm{~g}_{\mathrm{H} 2 \mathrm{O}}{ }^{-1}$ ).

By increasing the temperature to $175^{\circ} \mathrm{C}$, the reaction time for attaining the highest 5-HMF yield is shortened, making it possible to obtain a $5-\mathrm{HMF}$ yield of $63.1 \%$ for a glucose conversion of $87.9 \%$ with the NEEDLE-LTL catalyst, after only 90 min (Figure 10). The figure shows that glucose conversion increases progressively with the reaction time, and values of $100 \%$ are already reached after $60 \mathrm{~min}$ of reaction time. However, 5-HMF yield values attain a maximum, and then, despite the raise of conversion, degradation processes lead to a decrease in 5-HMF yield. 


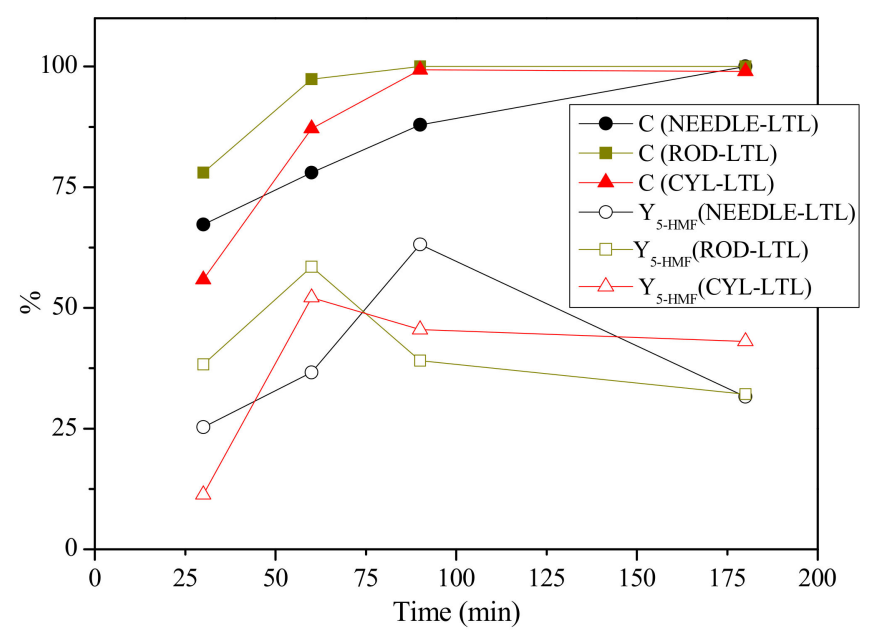

Figure 10. Kinetics of glucose dehydration (C: glucose conversion; Y: yield) (Experimental conditions: 0.15 g glucose, $0.05 \mathrm{~g}$ catalyst, $1.5 \mathrm{~mL}$ water, $3.5 \mathrm{~mL}$ MIBK, Temperature $\left.=175^{\circ} \mathrm{C}_{;} \mathrm{CaCl}_{2}=0.65 \mathrm{~g} \mathrm{~g}_{\mathrm{H} 2 \mathrm{O}}{ }^{-1}\right)$.

Another experimental parameter that has been evaluated is the glucose:catalyst weight ratio. The ratio has been varied between 1:1 and 10:1, by maintaining the amount of glucose and adding different amounts of NEEDLE-LTL. It can be observed that the conversion of glucose rises with the catalyst loading until a weight ratio of 3:1, which can be explained by the increment of available acid sites for glucose dehydration (Figure 11). Nevertheless, a higher amount of catalyst (ratio of 1:1) does not improve the conversion, although a slightly higher 5-HMF yield is attained. This could be explained by considering diffusional problems associated to the location of active sites in micropores.

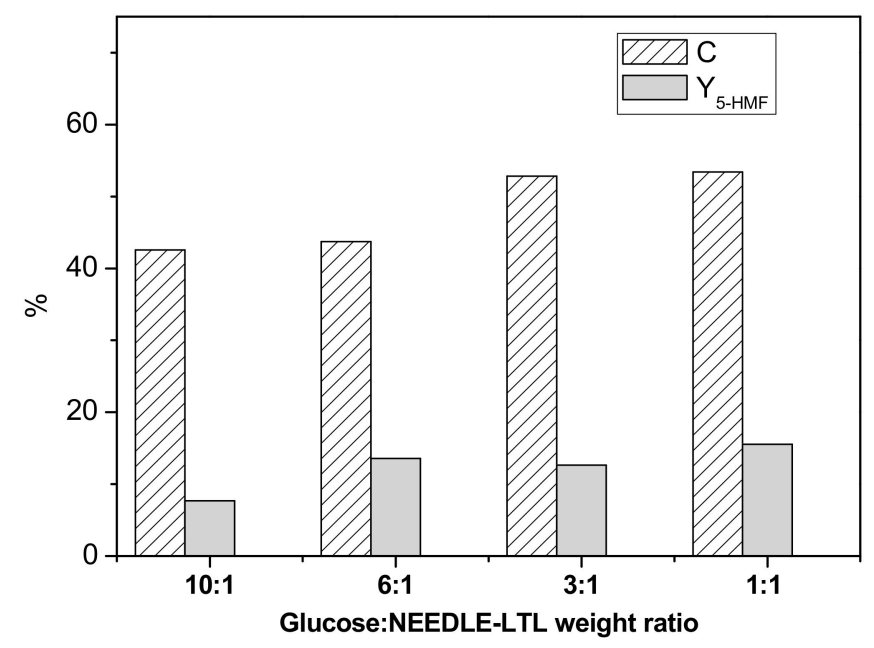

Figure 11. Influence of the glucose:catalyst (NEEDLE-LTL) weight ratio (C: glucose conversion; Y: yield) (Experimental conditions: 0.15 g glucose, 1.5 water, $3.5 \mathrm{~mL}$ MIBK, Temperature: $150{ }^{\circ} \mathrm{C}$; time: $60 \mathrm{~min}, \mathrm{CaCl}_{2}=0.65 \mathrm{~g} \mathrm{~g}_{\mathrm{H} 2 \mathrm{O}}{ }^{-1}$ ).

A key aspect in heterogeneous catalysis is the recovery of the solid catalyst to be used in successive catalytic runs. In order to carry out this study, a glucose:catalyst weight ratio of 1:1 was used, since a higher catalyst loading would minimize the loss of catalyst between cycles, produced by catalyst handling. The reaction was studied at $150{ }^{\circ} \mathrm{C}$, for $60 \mathrm{~min}$ (Figure 12). 


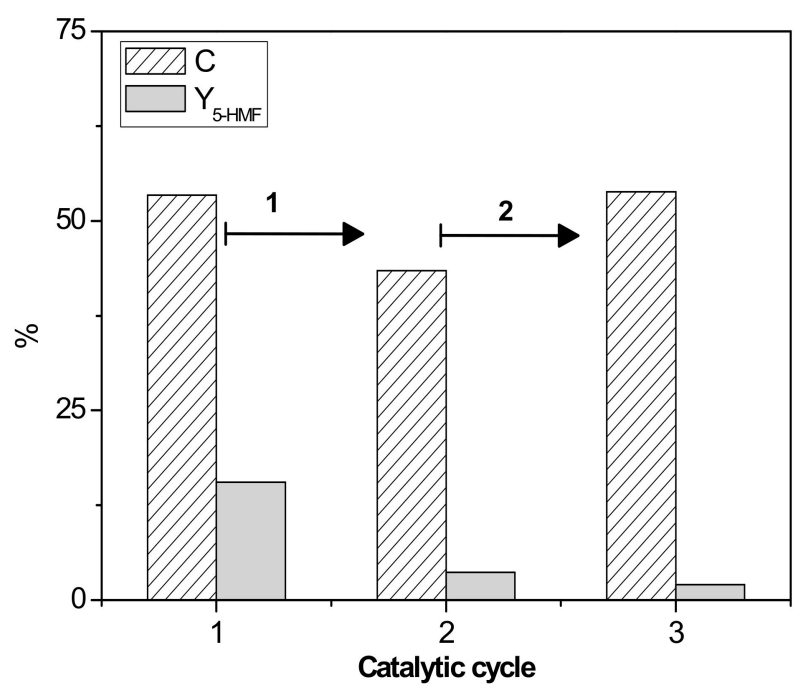

Figure 12. Reusing study of NEEDLE-LTL after (1) drying at $65^{\circ} \mathrm{C}$ and (2) washing with water/acetone (C: glucose conversion; Y: yield) (Experimental conditions: 0.15 g glucose, 0.15 g catalyst, 1.5 water, $3.5 \mathrm{~mL}$ MIBK, Temperature: $150{ }^{\circ} \mathrm{C}$; time: $\left.60 \mathrm{~min}, \mathrm{CaCl}_{2}=0.65 \mathrm{~g}_{\mathrm{H} 2 \mathrm{O}}{ }^{-1}\right)$.

After the first catalytic cycle, the solid catalyst was filtered and dried at $65^{\circ} \mathrm{C}$. The catalytic data reveal a decrease in glucose conversion from 53.4 to $43.4 \%$, although active sites involved in glucose dehydration to 5-HMF seem to be almost deactivated, since 5-HMF yield drastically diminishes from 15.5 to $3.7 \%$. After the second run, a water/acetone washing and filtration of the used solid was also carried out, recovering the glucose conversion, but the 5-HMF yield is still lower. Finally, the used catalyst was calcined until $550{ }^{\circ} \mathrm{C}$ for $2 \mathrm{~h}$ after the first catalytic reaction cycle in order to remove the organic fraction. However, the initial catalytic performance continued without recovery, with values of glucose conversion and 5-HMF yield of $100 \%$ and $4.52 \%$, respectively. In order to explain the reason of this behavior, the thermogravimetric analyses of used and fresh NEEDLE-LTL zeolite catalysts were performed (Figure 13). The fresh zeolite shows a weight loss of $10 \%$ between room temperature and $200{ }^{\circ} \mathrm{C}$, associated to the removing of adsorbed water, without any remarkable weight variation onwards until 900 . However, the used catalyst exhibits a high weight loss in the same temperature range, but with two distinguishable steps, which could be associated to the elimination of adsorbed water and MIBK, account for $20 \%$. Then, a progressive weight loss is observed, but with an important sloop change between 700 and $900{ }^{\circ} \mathrm{C}$. Thus, a weight loss of $22 \%$ is observed between 200 and $900{ }^{\circ} \mathrm{C}$, and the high temperature required to remove organic molecules could be explained by the strong interaction between the organic guest molecules with the catalyst surface inside the micropores. In this sense, a regeneration temperature of $550^{\circ} \mathrm{C}$ was not enough to remove organic species, which cover the active sites responsible of glucose dehydration to 5-HMF. The covering of active sites by carbonaceous deposits, as main cause of the decrease in catalytic activity, has been already reported for zeolites [23].

Therefore, it can be concluded that the LTL-zeolites can be used as heterogeneous acid catalysts for the dehydration of glucose to 5-hydroxymethylfurfural, attaining a maximum 5-HMF yield of $63.1 \%$ for a glucose conversion of $87.9 \%$, at $175^{\circ} \mathrm{C}$ after $90 \mathrm{~min}$, with the NEEDLE-LTL catalyst, formed by nanoparticles with a length of $4.46 \mu \mathrm{m}$ and a width of $0.63 \mu \mathrm{m}$. The diffusion of glucose molecules to the active sites present in LTL zeolites is favored by using needle and rod morphologies, but it is necessary to prepare hierarchical zeolites, where mesoporosity is a key feature for facilitating the access of reactants and the regeneration of active sites, thus delaying the catalyst deactivation. 


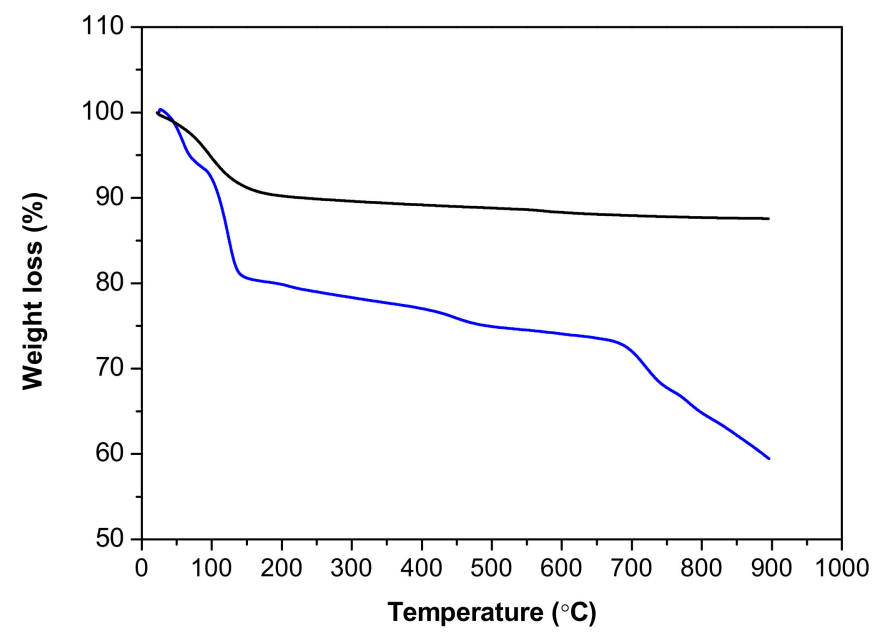

Figure 13. TG curves of fresh (black line) and used (blue line) (glucose:catalyst weight ratio $=1: 1$, $\mathrm{T}=150{ }^{\circ} \mathrm{C}$, time $=60 \mathrm{~min}$ ) NEEDLE-LTL-zeolite.

\section{Materials and Methods}

\subsection{Chemicals and Mterials}

Potassium hydroxide pellets (85\%) and ammonium nitrate were purchased from Merck (Darmstadt, Germany). Colloidal silica HS-40 was supplied by Sigma-Aldrich (Darmstadt, Germany). Aluminium sulfate hexadecahydrate $\left(\mathrm{Al}_{2}\left(\mathrm{SO}_{4}\right)_{3} .16 \mathrm{H}_{2} \mathrm{O}, 97 \%\right)$ was obtained from BDH Chemical Ltd, (Poole, UK). All chemicals were used without further purification. For the catalytic tests, the following chemicals have been utilized: glucose (Sigma-Aldrich, >99\%), fructose (Sigma-Aldrich, >99\%) and calcium chloride (VWR, Radnor, PA, USA, 97\%). Deionized water and methyl isobutyl ketone (MIBK, VWR, $98 \%$ ) have been used as solvents.

\subsection{Synthesis of L-Type Zeolites}

Short-rod shape L-type zeolite was synthesized by dissolving $\mathrm{KOH}(3.018 \mathrm{~g})$ and $\mathrm{Al}_{2}\left(\mathrm{SO}_{4}\right)_{3} \cdot 16 \mathrm{H}_{2} \mathrm{O}$ $(1.442 \mathrm{~g})$ with distilled water $(18.208 \mathrm{~g})$ in a polypropylene (PP) bottle. The mixture was magnetically stirred at room temperature to form a slightly cloudy solution. A clear silicate solution was prepared by mixing HS-40 (6.875 g) with distilled water (9.958 g) under stirring for $5 \mathrm{~min}$. To avoid gelation, the silicate solution was added dropwise into the aluminate solution under vigorous stirring for $5 \mathrm{~min}$. The solution with a final molar ratio of $10.0 \mathrm{~K}_{2} \mathrm{O}: 1 \mathrm{Al}_{2} \mathrm{O}_{3}: 20 \mathrm{SiO}_{2}: 800 \mathrm{H}_{2} \mathrm{O}$ was further aged at room temperature for $18 \mathrm{~h}$ under stirring prior to crystallization at $180{ }^{\circ} \mathrm{C}$ for 3 days. The solid product was then filtered and purified with distilled water until $\mathrm{pH} 7$ prior to freeze-drying. The zeolite powder in K-form (3.000 g) was then ion exchanged with ammonium nitrate $(1.5 \mathrm{M}, 100 \mathrm{~mL})$ at $25^{\circ} \mathrm{C}$ for $18 \mathrm{~h}$ before subjecting calcination at $480{ }^{\circ} \mathrm{C}$ for $4 \mathrm{~h}$ to produce protonated L-type zeolite (ROD-LTL). Similar procedures were used for preparing L-type zeolites with other morphologies (needle and cylinder) but using hydrogels of different molar compositions as stated in Table 4. The protonated L-type zeolite crystalline solids with short-rod, cylindrical and needle shapes were denoted as ROD-LTL, CYL-LTL and NEEDLE-LTL, respectively.

Table 4. Experimental conditions for the synthesis of L-type zeolites with different morphologies.

\begin{tabular}{|c|c|c|c|c|c|c|c|}
\hline & \multicolumn{4}{|c|}{ Molar Composition } & \multirow{2}{*}{ Aging (h) } & \multirow{2}{*}{$\begin{array}{c}\text { Synthesis } \\
\text { Temperature }\left({ }^{\circ} \mathrm{C}\right)\end{array}$} & \multirow{2}{*}{$\begin{array}{c}\text { Synthesis } \\
\text { Time (h) }\end{array}$} \\
\hline & $\mathrm{K}_{2} \mathrm{O}$ & $\mathrm{Al}_{2} \mathrm{O}_{3}$ & $\mathrm{SiO}_{2}$ & $\mathrm{H}_{2} \mathrm{O}$ & & & \\
\hline ROD-LTL & 10.0 & 1 & 20 & 800 & 18 & 180 & 72 \\
\hline NEEDLE-LTL & 10.2 & 1 & 20 & 1100 & 18 & 180 & 72 \\
\hline CYL-LTL & 10.2 & 1 & 20 & 1030 & 18 & 180 & 72 \\
\hline
\end{tabular}




\subsection{Characterization of LTL Zeolites}

XRD patterns were recorded using an AXS D8 diffractometer (Bruker, Rheinstetten, Germany) operating at $40 \mathrm{kV}$ and $10 \mathrm{~mA}(\mathrm{Cu} \mathrm{K} \alpha$ radiation, $\lambda=0.15418 \mathrm{~nm})$. The surface morphology of samples was observed using a JSM-6701F FESEM microscope (JEOL, Tokio, Japan). The infrared (IR) spectra were acquired using a System 2000 instrument (Perkin-Elmer, Waltham, MA, USA) using the KBr method (sample:KBr ratio = 1:50). The chemical composition of zeolites was also determined with an Optima 8300 inductively coupled plasma-optical emission spectrometer (ICP-OES). Textural properties were determined by an ASAP 2010 nitrogen adsorption analyzer (Micrometrics, Norcross, GA, USA) at $-196^{\circ} \mathrm{C}$. First, the sample (ca. $0.08 \mathrm{~g}$ ) was degassed under vacuum at $300^{\circ} \mathrm{C}$ overnight. The surface area and pore size distribution of samples were estimated using the Langmuir and DFT models, respectively. The total pore volume of the solids was determined from the nitrogen adsorbed volume at $\mathrm{P} / \mathrm{P}_{\mathrm{o}}=0.990$.

The FTIR spectra after pyridine adsorption were acquired using a 2000 FTIR spectrometer (Nicolet, Thermo Fisher Scientific, Waltham, MA, USA). Initially, the zeolite powder (ca. $0.01 \mathrm{~g}$ ) was ground and pressed into a self-supporting wafer $\left(\right.$ area $2 \mathrm{~cm}^{2}$ ) at 6.0 ton. The wafer was introduced into an IR vacuum cell and activated at $400{ }^{\circ} \mathrm{C}$ for $5 \mathrm{~h}$ under vacuum $\left(10^{-3} \mathrm{mbar}\right)$. The sample was cooled to $25{ }^{\circ} \mathrm{C}$ before the background spectrum of zeolite was recorded. Pyridine vapor was adsorbed onto the sample for $3 \mathrm{~min}$ before the excess pyridine vapor was evacuated. The FTIR spectra were recorded at $25^{\circ} \mathrm{C}$ using 200 scans with a resolution of $6 \mathrm{~cm}^{-1}$. The wafer was then heated at $150{ }^{\circ} \mathrm{C}$ for $1 \mathrm{~h}$ to remove weakly bound pyridine before the second IR spectrum was recorded. The wafer was heated again to $300{ }^{\circ} \mathrm{C}$ for $1 \mathrm{~h}$ before it was cooled to $25^{\circ} \mathrm{C}$ and scanned again with an IR spectrometer. The concentration of Lewis and Brönsted acid sites were calculated by using the molar integral extinction coefficients of $\varepsilon_{\text {Brönsted }}=3.03 \mathrm{~cm} \mathrm{\mu mol}^{-1}$ and $\varepsilon_{\text {Lewis }}=3.80 \mathrm{~cm} \mathrm{\mu mol}^{-1}$ [36].

X-ray photoelectron spectra were obtained with a PHI 5700 spectrometer (Physical Electronics, Eden Prairie, Minnesota, USA) with non-monochromatic $\mathrm{Mg} \mathrm{K \alpha}$ radiation ( $300 \mathrm{~W}, 15 \mathrm{kV}$, and $1253.6 \mathrm{eV}$ ) with a multi-channel detector. Spectra were recorded in the constant pass energy mode at $29.35 \mathrm{eV}$, using a $720 \mu \mathrm{m}$ diameter analysis area. Charge referencing was measured against adventitious carbon (C $1 \mathrm{~s}$ at $284.8 \mathrm{eV}$ ). The PHI ACCESS ESCA-V6.0 F software package was used for acquisition and data analysis. A Shirley-type background was subtracted from the signals. Recorded spectra were always fitted using Gaussian-Lorentzian curves in order to determine accurately the binding energies of the different element core levels.

${ }^{27} \mathrm{Al}$ MAS-NMR experiments were performed on an AV-400 (9.4 T) spectrometer (Bruker, Rheinstetten, Germany), using a BL-4 probe with zirconia rotors. The spectra were obtained using a spinning speed of $\mathrm{vR}=10 \mathrm{kHz}$, a pulse width of $1 \mu$ s corresponding to a $\pi / 12$ rad. Pulse length, a relaxation delay of $1 \mathrm{~s}$, and typically 1200 scans. The temperature-programmed desorption of ammonia $\left(\mathrm{NH}_{3}-\mathrm{TPD}\right)$ was carried out to evaluate the total surface acidity of catalysts. After cleaning of catalysts $(0.08 \mathrm{~g})$ with helium up to $550{ }^{\circ} \mathrm{C}$ and subsequent adsorption of ammonia at $100{ }^{\circ} \mathrm{C}$, the $\mathrm{NH}_{3}$-TPD was performed by raising the temperature from 100 to $550{ }^{\circ} \mathrm{C}$, under a helium flow of $40 \mathrm{~mL} \mathrm{~min}-1$, with a heating rate of $10^{\circ} \mathrm{C} \mathrm{min}-1$ and maintained at $550{ }^{\circ} \mathrm{C}$ for $15 \mathrm{~min}$. The evolved ammonia was analyzed by using a TCD detector of a gas chromatograph (Shimadzu GC-14A).

Thermogravimetric analyses (TGA) were performed with a TGA/DSC model 1 instrument (Mettler-Toledo, Columbus, OH, USA) heating from room temperature until $900{ }^{\circ} \mathrm{C}$ with a heating ramp of $10{ }^{\circ} \mathrm{C} \mathrm{min}-1$ under air flow of $50 \mathrm{~mL} \mathrm{~min}^{-1}$. The carbon content of spent catalysts was measured with a CHNS 932 analyzer (LECO, Madrid, Spain).

\subsection{Catalytic Reaction}

The catalytic performance of LTL-type zeolites in glucose dehydration was evaluated under batch conditions, by using a glass pressure tube equipped with threaded bushing $(15 \mathrm{~mL}$, pressure rated to 10 bars, Ace Glass, Vineland, NJ, USA) under magnetic stirring. In a typical experiment, $0.15 \mathrm{~g}$ of glucose, $0.05 \mathrm{~g}$ of catalyst, $1.5 \mathrm{~mL}$ of deionized water and $3.5 \mathrm{~mL}$ of methyl isobutyl ketone (MIBK) were introduced into the reactor. Reactors were always purged with nitrogen, prior to the catalytic 
study in order to minimize side reactions of HMF which decrease its yield. The mixture was heated with a thermostatically controlled oil bath. The reaction was quenched by submerging the reactor in a cool water bath, and the liquid phases were separated, filtered and the analysis of products was performed in both phases by high performance liquid chromatography (HPLC). A JASCO (Easton, MD, USA) instrument equipped with quaternary gradient pump (PU-2089), multiwavelength detector (MD-2015), autosampler (AS-2055), column oven (co-2065) using a Luna C18 reversed-phase column $(250 \mathrm{~mm} \times 4.6 \mathrm{~mm}, 5 \mu \mathrm{m})$ and a Rezex ROA-Organic Acid $\mathrm{H}^{+}$column $(8 \%, 300 \mathrm{~mm} \times 7.8 \mathrm{~mm}, 5 \mu \mathrm{m})$ (both supplied by Phenomenex (Torrance, CA, USA). Both glucose and fructose were monitored using a refractive index detector for aqueous phase, while 5-HMF production was monitored using a UV detector in both phases. The mobile phases consisted of pure methanol (flow rate $0.5 \mathrm{~mL} \mathrm{~min}^{-1}$ ) for the Luna $\mathrm{C} 18$, and deionized water (flow rate $0.35 \mathrm{~mL} \mathrm{~min}^{-1}$ ) for the Rezex ROA column, being the columns at room temperature and $40{ }^{\circ} \mathrm{C}$, respectively.

Author Contributions: Experiment: M.J.G.M., N.H.A., S.M.M.; Data Curation: C.G.S., S.M.; Writing-Original Draft Preparation: C.G.S., E.-P.N., P.M.T.; Writing-Review \& Editing: C.G.S., S.M., E.-P.N., P.M.T.; Supervision: E.-P.N., P.M.T.; Funding Acquisition: E.-P.N., P.M.T.

Funding: This research was funded by the Spanish Ministry of Economy and Competitiveness (RTI2018-94918-B-C44), FEDER (European Union) funds and FRGS (203/PKIMIA/6711642).

Acknowledgments: The authors thank the Servicios Centrales de Apoyo a la Investigación at University of Málaga for technical support. C.G.S. acknowledges the University of Málaga for a postdoctoral contract.

Conflicts of Interest: The authors declare no conflict of interest.

\section{References}

1. Werpy, T.; Petersen, G. Top Value Added Chemicals from Biomass Volume I-Results of Screening for Potential Candidates from Sugars and Synthesis Gas; National Renewable Energy Lab.: Golden, CO, USA, 2004; Volume 1.

2. Van Putten, R.J.; Van Der Waal, J.C.; De Jong, E.D.; Rasrendra, C.B.; Heeres, H.J.; De Vries, J.G. Hydroxymethylfurfural, A Versatile Platform Chemical Made from Renewable Resources. Chem. Rev. 2013, 113, 1499-1597. [CrossRef]

3. Alonso, D.M.; Bond, J.Q.; Dumesic, J.A. Catalytic conversion of biomass to biofuels. Green Chem. 2010, 12, 1493-1513. [CrossRef]

4. Wang, T.; Nolte, M.W.; Shanks, B.H. Catalytic dehydration of C 6 carbohydrates for the production of hydroxymethylfurfural (HMF) as a versatile platform chemical. Green Chem. 2014, 16, 548-572. [CrossRef]

5. Delidovich, I.; Leonhard, K.; Palkovits, R. Cellulose and hemicellulose valorisation: An integrated challenge of catalysis and reaction engineering. Energy Environ. Sci. 2014, 7, 2803. [CrossRef]

6. Corma, A.; Iborra, S.; Velty, A.; Corma Canos, A.; Iborra, S.; Velty, A. Chemical routes for the transformation of biomass into chemicals. Chem. Rev. 2007, 107, 2411-2502. [CrossRef] [PubMed]

7. Hu, L.; Tang, X.; Xu, J.; Wu, Z.; Lin, L.; Liu, S. Selective transformation of 5-hydroxymethylfurfural into the liquid fuel 2,5-dimethylfuran over carbon-supported ruthenium. Ind. Eng. Chem. Res. 2014, 53, 3056-3064. [CrossRef]

8. Gallezot, P. Conversion of biomass to selected chemical products. Chem. Soc. Rev. 2012, 41, 1538-1558. [CrossRef]

9. Rackemann, D.W.; Doherty, W.O. The conversion of lignocellulosics to levulinic acid. Biofuels Bioprod. Bioref. 2011, 5, 198-214. [CrossRef]

10. Nikolla, E.; Roman-Leshkov, Y.; Moliner, M.; Davis, M.E. “One-Pot” Synthesis of 5-(Hydroxymethyl)furfural from Carbohydrates using Tin-Beta Zeolite. ACS Catal. 2011, 1, 408-410. [CrossRef]

11. Yabushita, M.; Kobayashi, H.; Fukuoka, A. Catalytic transformation of cellulose into platform chemicals. Appl. Catal. B Environ. 2014, 145, 1-9. [CrossRef]

12. Climent, M.J.; Corma, A.; Iborra, S. Converting carbohydrates to bulk chemicals and fine chemicals over heterogeneous catalysts. Green Chem. 2011, 13, 520-540. [CrossRef]

13. Gandarias, I.; Arias, P.L. Heterogeneous acid-catalysts for the production of furan-derived compounds (furfural and hydroxymethylfurfural) from renewable carbohydrates: A review. Catal. Today 2014, 234, 42-58. 
14. García-Sancho, C.; Fúnez-Núñez, I.; Moreno-Tost, R.; Santamaría-González, J.; Pérez-Inestrosa, E.; Fierro, J.L.G.; Maireles-Torres, P. Beneficial effects of calcium chloride on glucose dehydration to 5-hydroxymethylfurfural in the presence of alumina as catalyst. Appl. Catal. B Environ. 2017, 206, 617-625. [CrossRef]

15. Moreno-Recio, M.; Santamaría-González, J.; Maireles-Torres, P. Brönsted and Lewis acid ZSM-5 zeolites for the catalytic dehydration of glucose into 5-hydroxymethylfurfural. Chem. Eng. J. 2016, 303, 22-30. [CrossRef]

16. Jiménez-Morales, I.; Moreno-Recio, M.; Santamaría-González, J.; Maireles-Torres, P.; Jiménez-López, A. Production of 5-hydroxymethylfurfural from glucose using aluminium doped MCM-41 silica as acid catalyst. Appl. Catal. B Environ. 2015, 164, 70-76. [CrossRef]

17. Jiménez-Morales, I.; Moreno-Recio, M.; Santamaría-González, J.; Maireles-Torres, P.; Jiménez-López, A. Mesoporous tantalum oxide as catalyst for dehydration of glucose to 5-hydroxymethylfurfural. Appl. Catal. B Environ. 2014, 154, 190-196. [CrossRef]

18. Yang, Y.; Hu, C.W.; Abu-Omar, M.M. Conversion of carbohydrates and lignocellulosic biomass into 5-hydroxymethylfurfural using $\mathrm{AlCl}_{3}$ center dot $6 \mathrm{H}(2) \mathrm{O}$ catalyst in a biphasic solvent system. Green Chem. 2012, 14, 509-513. [CrossRef]

19. Román-Leshkov, Y.; Dumesic, J.A. Solvent effects on fructose dehydration to 5-hydroxymethylfurfural in biphasic systems saturated with inorganic salts. Top. Catal. 2009, 52, 297-303. [CrossRef]

20. Teychené, J.; Roux-De Balman, H.; Galier, S. Role of the triple solute/ion/water interactions on the saccharide hydration: A volumetric approach. Carbohydr. Res. 2017, 448, 118-127. [CrossRef]

21. Combs, E.; Cinlar, B.; Pagan-Torres, Y.; Dumesic, J.A.; Shanks, B.H. Influence of alkali and alkaline earth metal salts on glucose conversion to 5-hydroxymethylfurfural in an aqueous system. Catal. Commun. 2013, 30, 1-4. [CrossRef]

22. Moreno-Recio, M.; Jiménez-Morales, I.; Arias, P.L.; Santamaría-González, J.; Maireles-Torres, P. The Key Role of Textural Properties of Aluminosilicates in the Acid-Catalysed Dehydration of Glucose into 5-Hydroxymethylfurfural. ChemistrySelect 2017, 2, 2444-2451. [CrossRef]

23. Xu, S.; Pan, D.; Hu, F.; Wu, Y.; Wang, H.; Chen, Y.; Yuan, H.; Gao, L.; Xiao, G. Highly efficient Cr/ $\beta$-zeolite catalyst for conversion of carbohydrates into 5-hydroxymethylfurfural: Characterization and performance. Fuel Process. Technol. 2019, 190, 38-46. [CrossRef]

24. Huang, Y.J.; Qi, G.R.; Chen, L.S. Effects of morphology and composition on catalytic performance of double metal cyanide complex catalyst. Appl. Catal. A Gen. 2003, 240, 263-271. [CrossRef]

25. Remy, M.J.; Stanica, D.; Poncelet, G.; Feijen, E.J.P.; Grobet, P.J.; Martens, J.A.; Jacobs, P.A. Dealuminated H-Y zeolites: Relation between physicochemical properties and catalytic activity in heptane and decane isomerization. J. Phys. Chem. 1996, 100, 12440-12447. [CrossRef]

26. Moulder, J.F.; Stickle, W.F.; Sobol, P.E.; Bombem, K.D. Handbook of X-ray Photoelectron Spectroscopy; Chastain, J., Ed.; Perkin-Elmer Corporation: Eden Prairie, MN, USA, 1992.

27. Ng, E.P.; Awala, H.; Tan, K.H.; Adam, F.; Retoux, R.; Mintova, S. EMT-type zeolite nanocrystals synthesized from rice husk. Microporous Mesoporous Mater. 2015, 204, 204-209. [CrossRef]

28. Valtchev, V.P.; Bozhilov, K.N. Transmission electron microscopy study of the formation of FAU-type zeolite at room temperature. J. Phys. Chem. B 2004, 108, 15587-15598. [CrossRef]

29. Xu, B.; Bordiga, S.; Prins, R.; van Bokhoven, J.A. Effect of framework Si/Al ratio and extra-framework aluminum on the catalytic activity of Y zeolite. Appl. Catal. A Gen. 2007, 333, 245-253. [CrossRef]

30. Mu, M.; Harvey, G.; Prins, R. Quantitative multinuclear MAS NMR studies of zeolites. Microporous Mesoporous Mater. 2000, 34, 281-290.

31. Chen, F.R.; Davis, J.G.; Fripiat, J.J. Aluminum coordination and Lewis acidity in transition aluminas. J. Catal. 1992, 133, 263-278. [CrossRef]

32. Galadima, A.; Muraza, O. Zeolite catalyst design for the conversion of glucose to furans and other renewable fuels. Fuel 2019, 258, 115851. [CrossRef]

33. Tang, Z.; Su, J. Direct conversion of cellulose to 5-hydroxymethylfurfural (HMF) using an efficient and inexpensive boehmite catalyst. Carbohydr. Res. 2019, 481, 52-59. [CrossRef] [PubMed]

34. Prat, D.; Wells, A.; Hayler, J.; Sneddon, H.; McElroy, C.R.; Abou-Shehada, S.; Dunn, P.J. CHEM21 selection guide of classical- and less classical-solvents. Green Chem. 2015, 18, 288-296. [CrossRef] 
35. Fúnez-Núñez, I.; García-Sancho, C.; Cecilia, J.A.; Moreno-Tost, R.; Pérez-Inestrosa, E.; Serrano-Cantador, L.; Maireles-Torres, P. Synergistic effect between $\mathrm{CaCl}_{2}$ and $\gamma-\mathrm{Al}_{2} \mathrm{O}_{3}$ for furfural production by dehydration of hemicellulosic carbohydrates. Appl. Catal. A Gen. 2019, 585, 117188. [CrossRef]

36. Choorefe, M.Y.; Juan, J.C.; Oi, L.E.; Ling, T.C.; Ng, E.P.; Noorsaadah, A.R.; Centi, G.; Lee, K.T. The role of nanosized zeolite y in the $\mathrm{H}_{2}$-free catalytic deoxygenation of triolein. Catal. Sci. Technol. 2019, 9, 772-782.

(C) 2019 by the authors. Licensee MDPI, Basel, Switzerland. This article is an open access article distributed under the terms and conditions of the Creative Commons Attribution (CC BY) license (http://creativecommons.org/licenses/by/4.0/). 